\title{
Methods of grain separation from single-layer grinding wheel topography
}

\author{
Metody wyodrębniania ziaren \\ z topografii czynnej powierzchni ściernicy jednowarstwowej
}

\section{ANNA BAZAN \\ ANDRZEJ KAWALEC *}

The paper presents results of research concerning methods used for determining grain separation from measured data representing single-layer grinding wheel topography. The methods apply information concerning determined threshold level (Threshold method) or concerning watershed segmentation (Watershed method). A method for determining the average level of bond was also proposed.

KEYWORDS: grinding wheel topography, grinding wheel wear, particle and pore analysis

The wheel topography affects the conditions of its contact with the workpiece, and so in addition to other factors (e.g. process adjustable grinding parameters) determines the course of grinding. During processing, the topography of the grinding wheel is constantly changing due to wear [1]. These changes, depending on their nature and intensity, can lead to different grinding effects. For example, many authors described the reduction of surface roughness (parameters $R a$ and $R z$ ) along with the wear of monolayer wheels [2, 3]. As a result of wear, the abrasive grains became less sharp (surface area flattened) and shaped the surface smoother [4-6]. During the operation of the grinding wheel, further active grains were revealed, which also contributed to the reduction of the roughness of the ground objects.

Study of wheel wear is of great importance in the context of the effective use of these abrasive tools. This particularly applies to monolayer wheels. Their cutting potential is associated only with one layer of super-hard abrasive and the cutting properties can not be restored in the process of dressing the grinding wheel.

In the case of wheel wear tests, it is important to describe this phenomenon in a quantitative way [7-9]. One of the methods is based on determining the parameters of the topography of the grinding wheel active surface (GWAS) and determining how these parameters change over the life of the grinding wheel.

Modern programs for the analysis of measurement data of surface topography, e.g. SPIP by Image Metrology [10] or MountainsMap by DigitalSurf [11], have modules for the analysis of particles and pores, so they can be used to calculate parameters of abrasive grains [1]. These calculations, however, require preliminary determination of selected parameters, which is a separate task.

\footnotetext{
* Mgr inż. Anna Bazan (abazan@prz.edu.pl), dr hab. inż. Andrzej Kawalec (ak@prz.edu.pl) - Politechnika Rzeszowska
}

In order to calculate grain parameters on the measured topography, the areas - particles that correspond to them must first be identified. From the point of view of creating a description of grinding wheel wear it is beneficial if one particle corresponds only to one grain. Parameters of the particles, e.g. their height or volume, are determined in relation to the cut-off plane (threshold level). In order to be able to follow the change of particle parameters during the durability of the grinding wheel, i.e. at various stages of its wear, the cut-off plane should run approximately at the same level. In other words, for a given grain at various stages of wear, the cut-off plane must be in the same place.

The article presents the possibilities of the SPIP 6.4.2 program in the scope of extracting grains from measured topographies, as well as the method of calculating the threshold level at various stages of wear of a single-layer grinding wheel.

\section{Subject of study}

The subject of the research was a topography of the active surface of a single-layer grinding wheel with a $\mathrm{cBN}$ abrasive with a grain number B35 at various stages of wear. Grinding wheel bond was nickel, applied by galvanic method. The thickness of the bond layer was $50 \div 60 \% \cdot d_{g}$. The grinding wheel was conical in shape, with an angle of cone of $140^{\circ}$ and an average diameter of the active surface of $87.2 \mathrm{~mm}$. The grinding wheel grounded Pyrowear 53 high-alloy steel with hardness above 81 HRA until the tool was completely worn, which was manifested by an intensive increase in the grinding force. The grinding wheel operated with a grinding speed of $27.4 \mathrm{~m} / \mathrm{s}$, a feed speed of $4250 \mathrm{~mm} / \mathrm{min}$ and a grinding depth of $20 \mu \mathrm{m}$.

Wheel topography was reproduced using replicas, which were made using the Struers RepliSet system. The material of the replica was a black silicone rubber with the possibility of reproducing details above $0.1 \mu \mathrm{m}$.

The InfiniteFocus microscope from Alicona with an $\times 20$ lens was used to measure the topography of GWAS replicas. The GWAS topography was measured five times, i.e. before the grinding start, and after reaching a specific material volume $V^{\prime}$ of 204, 476, 670 and $680 \mathrm{~mm}^{3} / \mathrm{mm}$. Six same GWAS measuring $2.25 \mathrm{~mm} \times 2.50 \mathrm{~mm}$ were measured at each stage of wear.

The processing of measurement data along with the separation of grains and determination of their parameters was carried out in the SPIP 6.4.2 program. The MountainsMap Premium 7.4 program is also equipped with a module for analyzing particles, but it contains fewer functions useful in the conducted research. 


\section{Methods of extracting grains}

In SPIP 6.4.2. Software, in the Particle \& Pore module for determining the parameters of particles and pores (peaks and valleys), these elements can be recognized on the basis of the Threshold level or Watershed segmentation [1]. For the tests aiming at the selection of the best method and parameters for the separation of grains, three maps of the wheel topography were selected at various stages of wear and with varying percentage of smears.

In the first place, the evaluation of the quality of grain separation from the bond was based on a visual evaluation of the results. Then, parameters such as the number, percentage surface area and the total particle volume as well as the mean value from the maximum particle heights were determined. It was checked how these parameters changed with the wear of the grinding wheel in relation to the new grinding wheel.

Based on the visual assessment of the topography map, it was possible to determine whether the GWAS had wear due to abrasion and / or micro-fracturing of grains, their removal from the bond and macro-fracturing, as well as the formation of stresses. Abrasion and/or micro-fracturing of grains leads to a reduction in their height, and thus to a reduction in the volume of particles and their average maximum height. The pull out grains from the bond and macro-fracturing reduces the number, percentage of surface area and the total volume of the particles. The smears primarily increase the total volume of the particles. Based on the dominant wear processes and their intensities on the analyzed topographies, the reliability of the grain separation results could be assessed.

The best results of extracting the grains from the measured topography were obtained by determining the cutoff level (Threshold method) in an automatic way. Parameters taking into account altitude information, e.g. maximum grain height or their volume, are determined in relation to the "zero" level, which can be automatically determined in the plane of the average 3D profile, at the level of the smallest or most common height value. In tests, the dominant value was taken as the reference level because it was related to the bond layer and did not depend on the number and height of peaks and valleys that were changing due to wear.

The disadvantage of the automatic determination of the cut-off level is the inability to separate the grains located close to each other (fig. 1c and fig. 1d). The recommended method for this method is the watershed segmentation (fig. $1 \mathrm{e}$ and fig. 1f), however, it did not allow to achieve the expected results despite the many parameters of the division, with the help of which it was possible to control the segmentation process. Depending on the segmentation parameters adopted, the most common errors were: dividing the grain into several fragments, unrecognizing some grains with little steep slopes or joining the areas of the bond to the grains.

An important drawback of both methods was the implementation of cutoff levels of particles at different heights depending on the degree of GWAS wear. The analysis of the new wheel topography indicated that the cutoff level was higher - that higher grain parts were worn than in the case of the topography of the grinding wheel used (fig. 1). For this reason, we developed our own script containing a level determination algorithm, below which points were rejected for further analysis of the particles.

\section{Method of determining the level of particle isolation}

In order to determine the level of the particle cut-off, one should first calculate the average level of the bond, i.e. the value of the vertical coordinate, representing the average height of the measurement points corresponding to the bond. This level was determined on the basis of the following premises resulting from the construction of the grinding wheel and visual assessment of the topography maps obtained:

- three characteristic areas can be distinguished on GWAS topographies: grains forming peaks above the bond, bond and recesses in the bond, resulting, for example, from the pull put grains from the bond;

- on the bearing curve (Abbott curve) the grains are approximately the area of peaks, the valleys in the bond are associated with the recesses, and the bond is the core (fig. 2);

- in the area of the bond the differences in the height of the points are relatively small compared to grains and recesses after grains, so in order to determine the level of the bond one should find a fragment of the material share curve with the smallest inclination;

- the boundaries between the bond and the grains as well as the bond and valleys are not clear and are related to specific threshold values.

After analyzing the topography maps of different grinding wheels, by means of which different volumes of material were removed, it was found that the bond occupies not less than $43 \%$ of the measured surfaces. The areas of grains and recesses on the topography surveyed were marked with reserve to ensure that the remaining part belongs only to the bond.

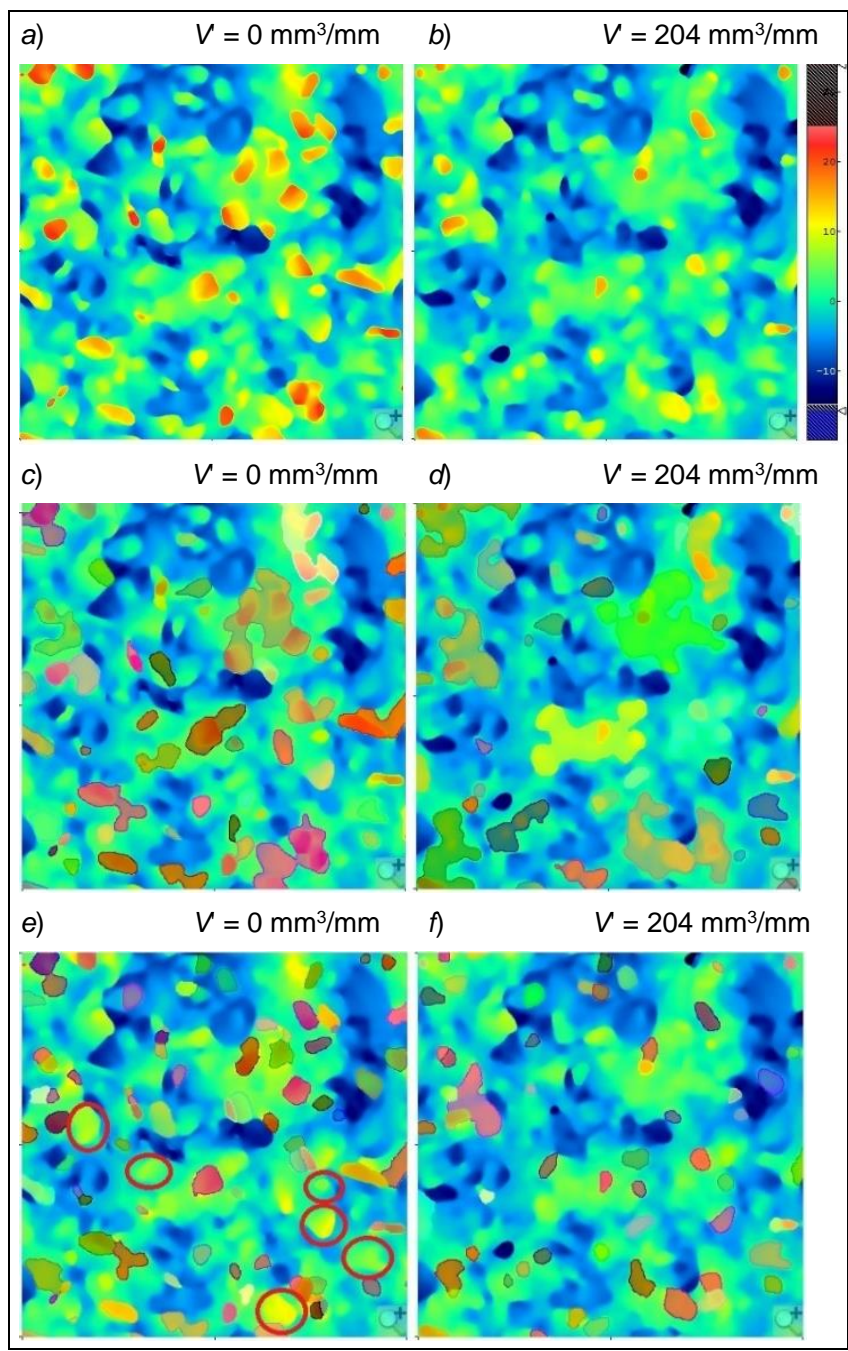

Fig. 1. Maps $0.5 \mathrm{~mm} \times 0.5 \mathrm{~mm}$ on the topography of the new grinding wheel (a) and the grinding wheel after specific material volume $V^{\prime}=204 \mathrm{~mm}^{3} / \mathrm{mm}$ and the corresponding maps with the particles identified by the Threshold method $(c, d)$ and Watershed $(e, f)$. The grains which are not particles on $(e)$ are marked with red color and they were recognized as particles in the next stage of grinding wheel research $(f)$ 


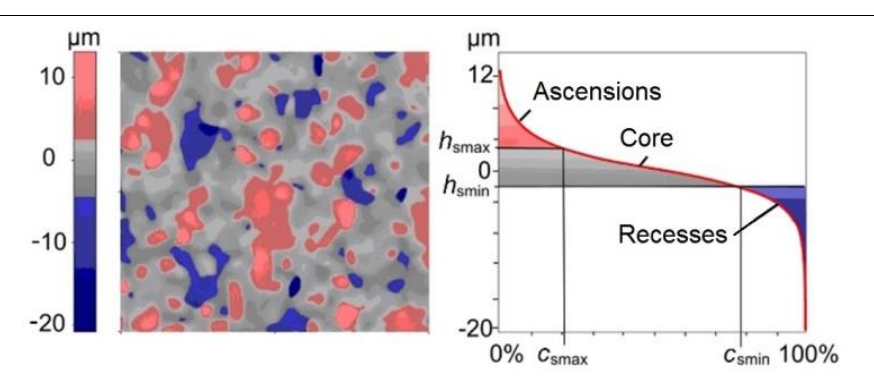

Fig. 2. Areas of grains, bonds and recess in the bond and the corresponding fields on the material share curve

It was assumed that the bond is more likely to occupy more than $40 \%$ of the surface area on topography maps. Therefore, the limit values of the bond level were determined by searching on the Abbott curve a fragment with a span equal to $40 \%$ of the material and secant share forming the smallest angle with the axis of the abscissae (fig. 3).

The average height of all measuring points, which correspond to the determined part of the material share curve, was assumed as the bond level. The cut-off level for further analyzes was raised in relation to the average level of the adhesive by $10 \mu \mathrm{m}$. This served to remove a larger number of measuring points corresponding to the bond and low-lying grains, which improved the quality of recognition of individual grains.

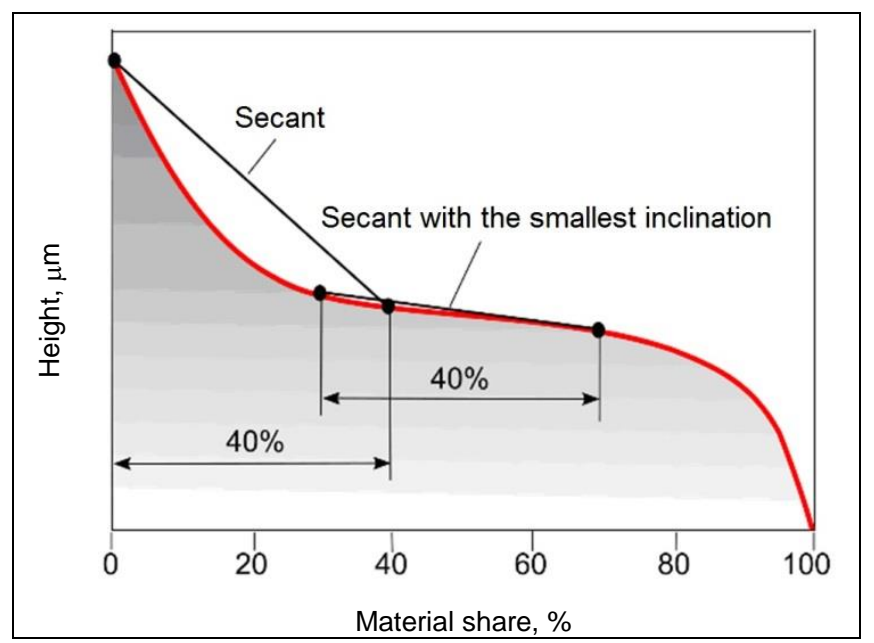

Fig. 3. Abbott and secant curve with the smallest inclination

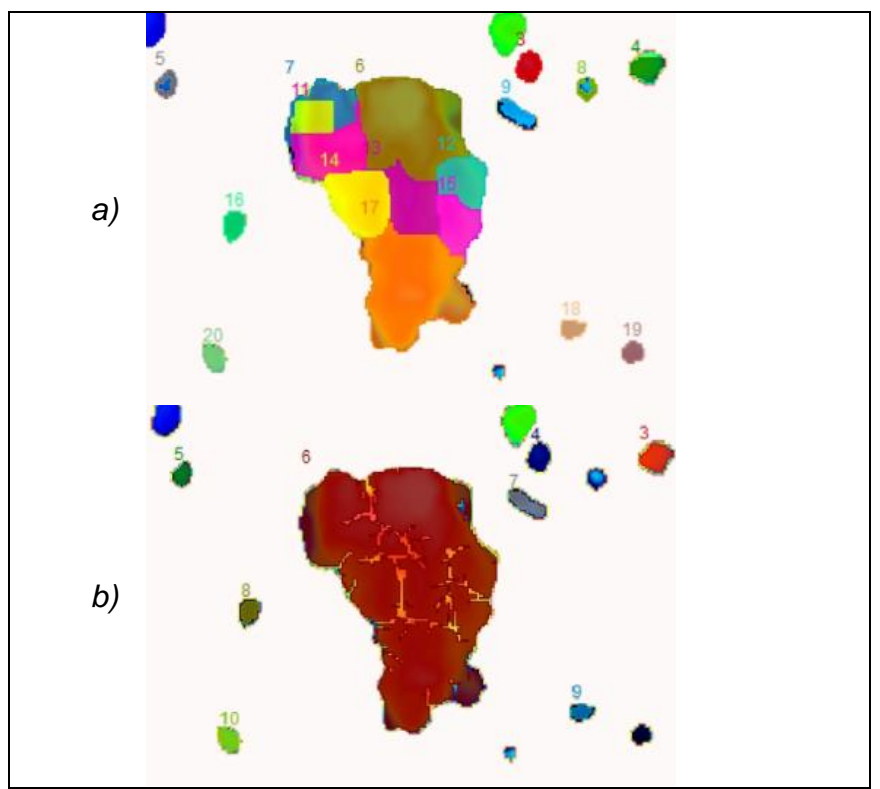

Fig. 4. Separation of the particles using the Watershed (a) and Threshold $(b)$ methods for the GWAS
After removing the points from the topography below the determined cut-off level, the grain separation gave satisfactory results when using the Watershed and Threshold methods without automatically setting the cut-off level. However, there was a significant difference in the situation of smears. Exemplary results of segmentation and separation of particles using both methods in the case of smeared GWAS are shown in fig. 4. The watershed segmentation led to the separation of many particles in the area of one smear. In the case of segmentation using the Threshold command, the smear has been recognized as a single area. It was therefore concluded that the Threshold method, in contrast to the watershed segmentation, gave satisfactory effects of particle separation.

Fig. 5 shows examples of particles separated by means of the described methodology on a new grinding wheel and grinding wheel after achieving the specific material volume $V^{\prime}=204 \mathrm{~mm}^{3} / \mathrm{mm}$.

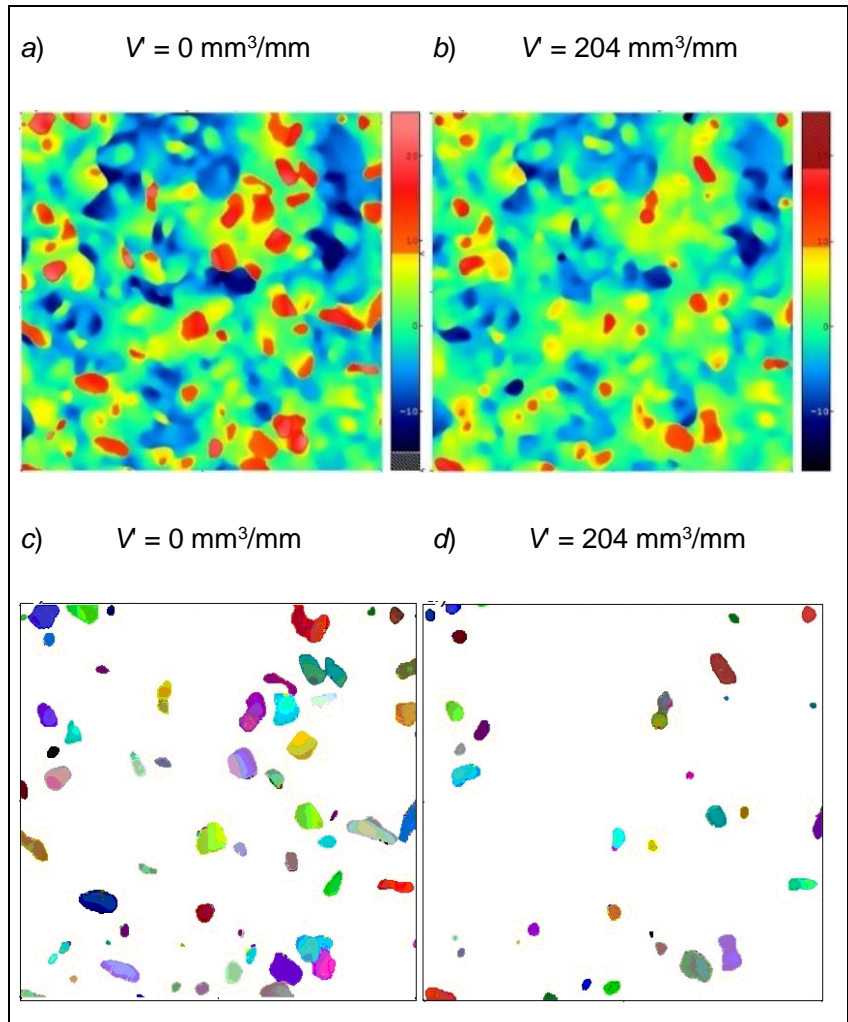

Fig. 5. Particles (red areas) above the calculated cut-off level for a new and used grinding wheel $(a, b)$ and particles separated with the Threshold command after removing points below the cut-off level $(c, d)$

\section{Conclusions}

Available software for surface topography analyzes gives you the ability to automatically determine the level of cut off of particles and pores. Unfortunately, while analyzing the GWAS topography at various stages of tool wear carried out in two tested programs, it was noticed that the cut-off level was not constant, so that the determined particle parameters were not calculated from the same base area over the entire lifetime of the grinding wheel. For this reason, we have developed our own algorithm for determining the level of particle segmentation. After removing the measurement points located below the cut-off level, the particles were recognized by the Threshold command and this cut-off level.

Similarly, it is also possible to process the measured GWAS topographies to determine the parameters of deep recesses in the bond, resulting from the removal of grains from the bond. 
Quantitative analysis of abrasive found on GWAS at various stages of grinding wheel wear and analysis of deep recesses can be the basis for inferring wear processes, their types, the dominant form of wear and its intensity.

\section{REFERENCES}

1. Bazan A., Kawalec A., Krok M., Chmielik I. „Analiza wybranych parametrów ziaren ściernic z CBN na podstawie pomiarów topografii”. Mechanik. 87, 8-9 (2014): pp. 49-52.

2. Aspinwall D. i.in: "Profiled superabrasive grinding wheels for the machining of a nickel based superalloy". CIRP Annals Manufacturing Technology. 56, 1 (2007): pp. 335-338.

3. Shi Z., Malkin S. "Wear of electroplated CBN grinding wheels". Journal of Manufacturing Science and Engineering. 128, 1 (2005): pp. 110-118.

4. Shi Z., Malkin S. "An investigation of grinding with electroplated CBN wheels". CIRP Annals - Manufacturing Technology. 52, 1 (2003): pp. 267-270.

5. Hwang T.W., Malkin S., Evans C.J. "High speed grinding of silicon nitrid with electroplated diamond wheels. Part 2: Wheel topography and grinding mechanisms". Journal of Manufacturing Science and Engineering. 122, 1 (1999): pp. 42-50.

6. Upadhyaya R., Fiecoat J. "Factors affecting grinding performance with electroplated CBN wheels". CIRP Annals - Manufacturing Technology. 56, 1 (2007): pp. 339-342.

7. Bazan A., Kawalec A. „Topografia czynnej powierzchni ściernicy z CBN ze spoiwem galwanicznym”. Mechanik. 86, 8-9 (2013): pp. 38-45

8. Kawalec A., Bazan A., Krok M., Chmielik I. „Porównanie wyników badań stykowych dotyczących parametrów topografii GWAS ściernic z CBN zmieniających się wraz z jej zużyciem". Mechanik. 87, 8-9, CD (2015): pp. 190-193.

9. Kacalak W., Tandecka K., Lipiński D., Szafraniec F., Socha E. „Metody identyfikacji zmian stanu czynnej powierzchni ściernic w wyniku starcia, zalepiania lub wykruszania ziaren"'. Mechanik. 87, 8-9 (2014): pp. 193-199.

10. www.imagemet.com (18.05.2018).

11. www.digitalsurf.com (18.05.2018).

Translation of scientific articles, their computer composition and publishing them on the website www.mechanik.media.p by original articles in Polish is a task financed from the funds of the Ministry of Science and Higher Education designated for dissemination of science. 